\title{
Study of o-fluorbenzonal electrochemical behavior with the carbon electrode using voltammetry
}

\author{
Galina Slepchenko ${ }^{1}$, Elena Mikheeva ${ }^{1}$, Olga Mezentseva ${ }^{1}$ and Nikolay Zaytsev $^{2}$ \\ ${ }^{1}$ National Research Tomsk Polytechnic University, Institute of nature resources, 634050 Tomsk, Russia \\ ${ }^{2}$ Moscow Technological University, 119454 Moscow, Russia
}

\begin{abstract}
A high sensitive stripping voltammetric method was for the first time proposed for determination of o-fluorbenzonal. This method is based on the ability to be electrochemically reduced with the carbon electrodes of different types. The working conditions of o-fluorbenzonal voltammetric determination are: $\mathrm{pH}$ of the background electrolyte, electrolysis potential and time scan rate. The effective dissociation constant of various forms of o-fluorbenzonal, number of electrons involved in the electrode process were calculated.
\end{abstract}

\section{Inroduction}

To solve the problem of drug provision of the citizens with modern Russian drugs domestic drugs need to be developped. At the Department of Biotechnology and Organic Chemistry of National Research Tomsk Polytechnic University the drug of o-fluorbenzonal (galonal) was synthesized, it can be used as an antiepileptic drug, like other barbiturates. Figure 1 shows its chemical structure.

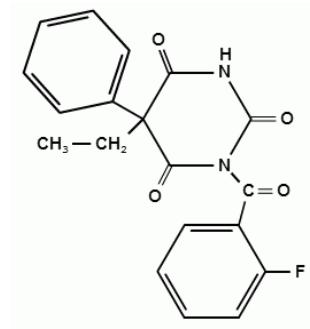

Fig1. Structure of o-fluorbenzonal

Along with this, the present substance has an enzyme-inducing activity, like phenobarbital, and therefore, may be recommended to enhance the antitoxic function of the liver [1] including for treatment of extrahepatic cholestasis [2]. Since the drug belongs to the group of barbiturates with the ability to cumulate, dose adjustments depending on the patient organism for the prevention of toxic effects of overdose and accompanied by inhibition of the respiratory center is nessesary [3].

Due to the high requirements to the quality of drugs, the importance of the use of modern standardized methods for analysis increases. The most versatile method is the voltammetry. It is widely used for determination of trace amounts of substances, in particular organic ones.

The aim of the work was to study the electrochemical behavior of o-fluorbenzonal on the carbon electrodes by the differential voltammetry.

\section{Experiment}

The measurements were carried out using the carbon-coated (CCE) and glassy carbon electrodes (GCE), and the saturated silver chloride electrode (SCE) was a reference electrode. Oxygen from the solution was removed by a stream of nitrogen with oxygen mass fraction not more than $0.01 \%$ (GOST 9293-74). The voltammograms were recorded on the voltammetric complex STA (TU4215-001-20694097-98) in differential pulse mode.

$\mathrm{PH}$ was determined using the portable $\mathrm{pH}-$ meter ( $\mathrm{pH}-673$ ). The error in determining solution $\mathrm{pH}$ did not exceed \pm $0.1 \%$.

The initial solution containing $1000.0 \mathrm{mg} / \mathrm{dm}^{3}$ of o-fluorbenzonal was prepared by dissolving the sample in dymethylformamide (DMF).

Corresponding author: slepchenkogb@mail.ru

(C) The Authors, published by EDP Sciences. This is an open access article distributed under the terms of the Creative Commons Attribution License 4.0 (http://creativecommons.org/licenses/by/4.0/). 


\section{Results and discussion}

To determine o-fluorbenzonal (galonal), a highly sensitive method of differential voltammetry was first proposed, it is based on its ability to be electrochemically reduced with the carbon-containing electrodes of different types.

The graphite (GE) and glassy carbon (GCE) electrodes were used as working, the first one is impregnated with polyethylene and paraffin in a vacuum.

These electrodes were used due to their high chemical and electrochemical stability, a wide area of the working potentials, and mechanical surface renewal simplicity. The potential for reduction of organic matter is determined by the composition, structure and degree of adsorption on the graphite hexagons having the $\pi$-band structure. The structural similarity of the electrode material and stereospecific adsorption, apparently favored by the transfer of electrons and reversible reduction of o-fluorbenzonalon the graphite electrodes. The greatest value of the analytical signal, least residual current, and better reproducibility in the voltammogram signals were observed on the glassy carbon electrode, which was selected as working.

The advantages of the glassy carbon electrode can also include high chemical resistance in corrosive environments, non-porousity, and high hardness. Also, the glassy carbon electrodes are commercially available, so it is not required for the researchers to produce their own ones. The potential of the peak of o-fluorbenzonal on the GCE is $-1.38 \pm 0.05 \mathrm{~V}$.

The voltammogram of o-fluorbenzonal electroreduction on the GCE is shown in Figure 2.

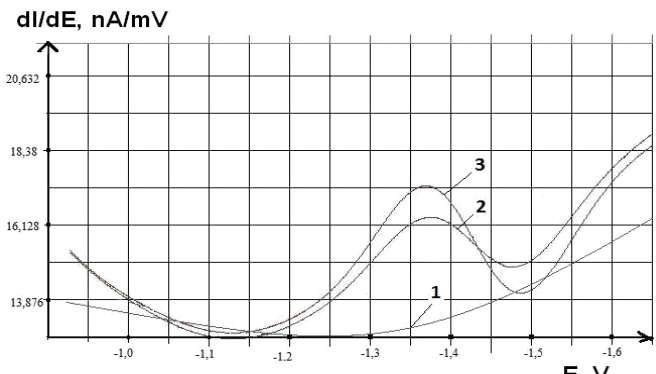

Fig2. The voltammogram of o-fluorbenzonal elecroreduction on the GCE, $w=50 \mathrm{mV} / \mathrm{sec}, \mathrm{E}_{\mathrm{e}}=-0.7 \mathrm{~V}, \tau_{\mathrm{e}}=30 \mathrm{sec}$ : 1 - the background electrolyte $0.1 \mathrm{MNaH}_{2} \mathrm{PO}_{4} ; 2-\mathrm{C}_{\text {o-fluorbenzonal }}=0.002 \mathrm{mg} / \mathrm{ml} ; 3-\mathrm{C}_{\text {o-fluorbenzonal }}=0.004 \mathrm{mg} / \mathrm{ml}$.

To select the background electrolyte,electroreduction of galonal was investigated in the solutions: $0.1 \mathrm{M} \mathrm{NaH}_{2} \mathrm{PO}_{4}$, $0.01 \mathrm{M} \mathrm{Na}_{2} \mathrm{~B}_{4} \mathrm{O}_{7}, 0.1 \mathrm{M} \mathrm{Na}_{2} \mathrm{CO}_{3}, 0.1 \mathrm{M} \mathrm{KCl}, 0.1 \mathrm{M} \mathrm{Na}_{3} \mathrm{PO}_{4}$. All of these electrolytes can be used for the voltammetric determination of o-fluorbenzonal but the working background electrolyte was chosen $0.1 \mathrm{M} \mathrm{Na}_{3} \mathrm{PO}_{4}$, with help of which the distinct peaks of electroreduction are recorded with good reproducibility; the relative standard deviation $\mathrm{Sr}$ is less than 0.05 (Figure 3).

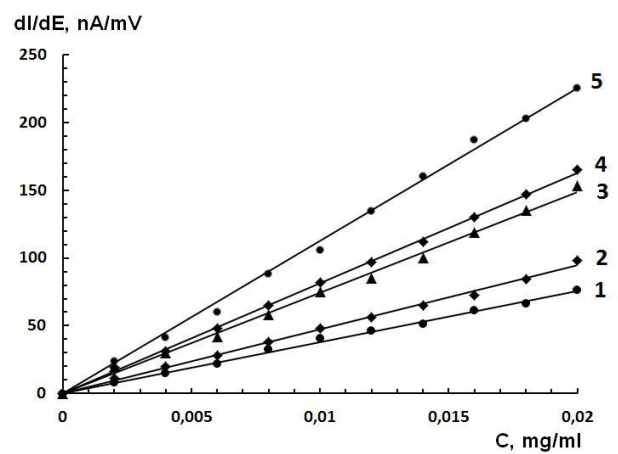

Fig3. The calibration curve of the o-fluorbenzonal electroreduction current dependence in different background electrolytes of the GCE, ${ }^{2}=50 \mathrm{mV} / \mathrm{sec}: 1-0.1 \mathrm{M} \mathrm{NaH}_{2} \mathrm{PO}_{4} ; 2-0.01 \mathrm{M} \mathrm{Na}_{2} \mathrm{~B}_{4} \mathrm{O}_{7} ; 3-0.1 \mathrm{M} \mathrm{Na}_{2} \mathrm{CO}_{3} ; 4-0.1 \mathrm{M} \mathrm{KCl} ; 5-0.1 \mathrm{M} \mathrm{Na}_{3} \mathrm{PO}_{4}$.

It is known that the organic substance can be adsorbed on the carbon-coated electrodes due to the structural interaction of adsorbate (organic matter-molecule) and the adsorbent (the electrode). The dependence of the current value of o-fluorbenzonal electrochemical reduction is shown in Figure 4. Figure shows that the optimum value of the adsorption concentration potential for galonal on the glassy carbon electrode surface is - $(0.5-0.6) \mathrm{V}$. 


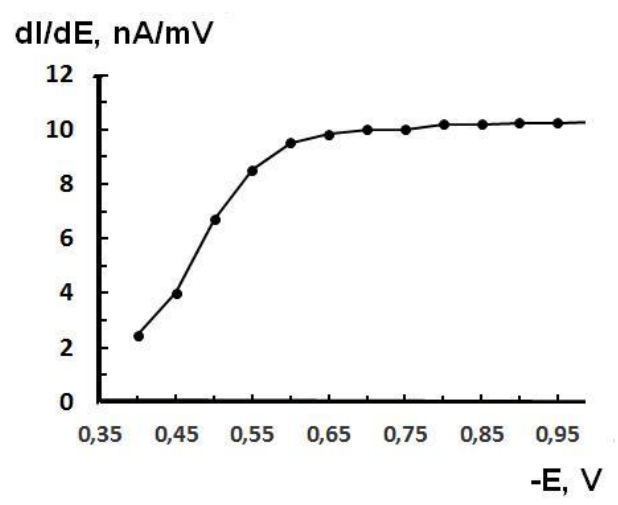

Fig4. The dependence of elecroreduction current of o-fluorbenzonal on electrolysis potential of the GCE: the background electrolyte $0.1 \mathrm{M} \mathrm{Na}_{3} \mathrm{PO}_{4}, \mathrm{C}_{\text {o-fluorbenzonal }}=2 \mathrm{mg} / \mathrm{l}$ in DMF, $\mathrm{t}_{\mathrm{e}}=30 \mathrm{sec}, \mathrm{w}=50 \mathrm{mV} / \mathrm{sec}$.

The dependence of the current value of galonal electroreduction on the electrolysis time of the electrode in the solution demonstrates the role of adsorption processes. The dependence of the electroreduction current of ofluorbenzonal on pre-adsorption accumulation time is shown in Figure 5. Figure shows that the pre-accumulation time of galonal should not exceed 30 seconds.

\section{$\mathrm{dl} / \mathrm{dE}, \mathrm{nA} / \mathrm{mV}$}

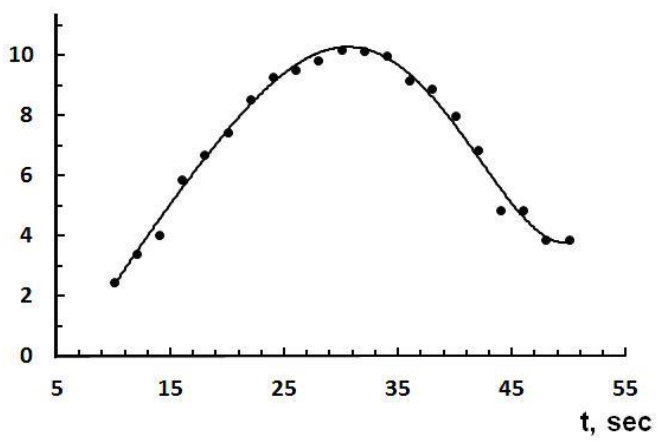

Fig5. The dependence of elecroreduction current of o-fluorbenzonal on electrolysis time on the GCE: the background electrolyte - 0.1 $\mathrm{M} \mathrm{Na}_{3} \mathrm{PO}_{4}, \mathrm{C}_{\mathrm{o} \text {-fluorbenzonal }}=2 \mathrm{mg} /$ lin DMF, $\mathrm{E}_{\mathrm{e}}=-0.7 \mathrm{~V}, \mathrm{w}=50 \mathrm{mV} / \mathrm{sec}$.

To increase the detection sensitivity, the differential voltammograms shooting mode was applied. The advantage of this type of shooting is the possibility of obtaining a distinct peak reducing the value of the measurement error of the analytical signal. When registering voltammograms, the scan rate of polarizing voltage of $50 \mathrm{mV} / \mathrm{sec}$ was selected. At higher speeds, detection sensitivity increased but the residual current increases at the same time. Using slower speeds significantly reduces the magnitude of the analytical signal of o-fluorbenzonal electroreduction.

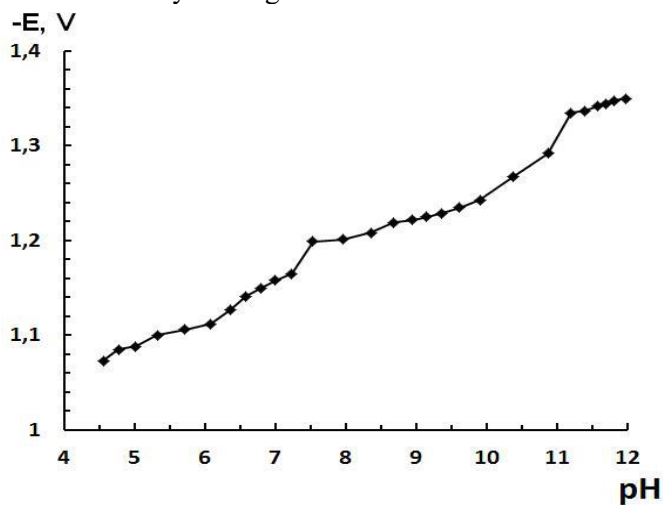

Fig6. The dependence of elecroreduction current of o-fluorbenzonal on $\mathrm{pH}$ on the GCE: $\mathrm{C}_{\mathrm{o}-\text { fluorbenzonal }}=2 \mathrm{mg} / \mathrm{l}$ in $\mathrm{DMF}, \mathrm{E}_{\mathrm{e}}=-0.7 \mathrm{~V}, \mathrm{w}=$ $50 \mathrm{mV} / \mathrm{sec}$. 
The redox properties of o-fluorbenzonal (galonal) have not been previously studied. The paper presents the research of the electrochemical reduction process of o-fluorbenzonal depending on $\mathrm{pH}$, which is an important factor in the voltammetric determination of organic substances. The dependence of the electrochemical reduction potential on $\mathrm{pH}$ on the CGE is shown in Figure 6. The dependence of the maximum potential of the cathodic peak on $\mathrm{pH}$ is complex. With an increase in concentration of hydroxide-ion, the peak shifts to the cathode region, it means to the difficulty in the recovery process of the organic matter, which appears to be linked to the preceding protolytic deprotonation reaction of the galonal molecular form. Deprotonation step may precede the electron attachment of the depolarizer molecule to the electrode or occur simultaneously. The effective values of the dissociation constants of different forms of ofluorbenzonal were calculated, which are $3.16 \cdot 10^{-8}$ and $6.31 \cdot 10^{-12}$ respectively.

With an increase in $\mathrm{pH}$ of the background electrolyte, the organic matter changes its form in the solution, it is determined by the protolytic balance. Since an electron breaking from a neutral particle requires less energy than from the cationic potential, the electroreduction potential of o-fluorbenzonal in alkaline solution (where the neutral form of the galonal molecule dominates) is lower than in acidic.

The peak potential of the organic compound in the solution is not determined by the ratio of the concentrations of oxidized and reduced forms in the Nernst equation, it is caused by the transfer kinetics of the electrons, and, perhaps, protons dependent on adsorption of organic matter and structure of double electric layer. In this case, the $\mathrm{pH}$ dependence of $\mathrm{E}$ on $\mathrm{pH}$ may be expressed by:

$$
\mathrm{E}_{1} / 2=\mathrm{E}^{\circ}+\frac{\mathrm{RT}}{\mathrm{zF}} \ln \alpha_{H+}^{v}=\mathrm{E}^{\circ}-\frac{R T}{z F} p H
$$

where $v$ - the number of protons involved in the electrode process.

The slope angle tangent of $\mathrm{E}$ depending on $\mathrm{pH}$ is 0.0589 , indicating participation of one electron and one proton in the electrode processes.

The background electrolytes of $0.1 \mathrm{M} \mathrm{Na}_{3} \mathrm{PO}_{4}(\mathrm{pH} 4-7)$ recommended for voltammetric determination of galonal have a $\mathrm{pH}$ optimum when o-fluorbenzonal is in the stable protonated form.

\section{Conclusion}

Thus, the operating conditions for the voltammetric determination of o-fluorbenzonal are determined on the basis of this research namely, background electrolyte - a solution of $0.1 \mathrm{M} \mathrm{Na} \mathrm{PO}_{4}$, electrolysis time - 30 seconds, electrolysis potential - -0,6V. Subsequently, using these conditions, a quantitative determination method will be developed.

\section{References}

[1] A.Saratikov Regulators detoxification enzyme systems include nitrogen-containing compounds 264 p (2002)

[2] T. Novozheeva, I. Chursina, A. Novozheeva, A. Saratikov 2004 Pharm. Chem. J. 38, 1 3-4 (2004)

[3] T.Vergeichik Toxicological chemistry 400 p (2009)

Conflict of interest: The authors declare that they have no conflict of interest. 